\title{
BMJ Open The costs of diabetes among Australians aged 45-64 years from 2015 to 2030: projections of lost productive life years (PLYs), lost personal income, lost taxation revenue, extra welfare payments and lost gross domestic product from Health\&WealthMOD2030
}

\author{
Deborah Schofield, ${ }^{1,2,3}$ Rupendra N Shrestha, ${ }^{1}$ Michelle M Cunich, ${ }^{1}$ \\ Megan E Passey, ${ }^{4}$ Lennert Veerman, ${ }^{5}$ Robert Tanton, ${ }^{6}$ Simon J Kelly ${ }^{6}$
}

To cite: Schofield D, Shrestha RN, Cunich MM, et al. The costs of diabetes among Australians aged 4564 years from 2015 to 2030 : projections of lost productive life years (PLYs), lost personal income, lost taxation revenue, extra welfare payments and lost gross domestic product from Health\&WealthMOD2030. BMJ Open 2017;7:e013158. doi:10.1136/bmjopen-2016013158

- Prepublication history for this paper is available online. To view these files please visit the journal online (http://dx.doi.org/10.1136/ bmjopen-2016-013158).

Received 24 June 2016 Revised 26 October 2016 Accepted 30 November 2016

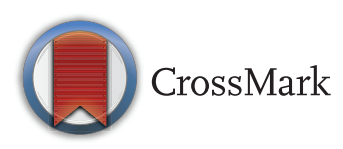

For numbered affiliations see end of article.

Correspondence to Dr Michelle M Cunich; michelle.cunich@sydney.edu.au

\section{ABSTRACT}

Objectives: To project the number of people aged 45-64 years with lost productive life years (PLYs) due to diabetes and related costs (lost income, extra welfare payments, lost taxation revenue); and lost gross domestic product (GDP) attributable to diabetes in Australia from 2015 to 2030.

Design: A simulation study of how the number of people aged 45-64 years with diabetes increases over time (based on population growth and disease trend data) and the economic losses incurred by individuals and the government. Cross-sectional outputs of a microsimulation model (Health\&WealthMOD2030) which used the Australian Bureau of Statistics' Survey of Disability, Ageing and Carers 2003 and 2009 as a base population and integrated outputs from two microsimulation models (Static Incomes Model and Australian Population and Policy Simulation Model), Treasury's population and labour force projections, and chronic disease trends data.

Setting: Australian population aged 45-64 years in 2015, 2020, 2025 and 2030

Outcome measures: Lost PLYs, lost income, extra welfare payments, lost taxation revenue, lost GDP.

Results: 18100 people are out of the labour force due to diabetes in 2015, increasing to 21400 in 2030 (18\% increase). National costs consisted of a loss of \$A467 million in annual income in 2015, increasing to \$A807 million in 2030 (73\% increase). For the government, extra annual welfare payments increased from \$A311 million in 2015 to \$A350 million in 2030 (13\% increase); and lost annual taxation revenue increased from \$A102 million in 2015 to \$A166 million in 2030 (63\% increase). A loss of \$A2.1 billion in GDP was projected for 2015 , increasing to $\$ A 2.9$ billion in 2030 attributable to diabetes through its impact on PLYs. Conclusions: Individuals incur significant costs of diabetes through lost PLYs and lost income in

\section{Strengths and limitations of this study}

- The study is the first in Australia and internationally to project the costs of older workers exiting the labour market due to diabetes from the perspective of individuals, government and the nation over a long time horizon (ie, out to 2030).

- The study uses a microsimulation model on the impacts of ill-health, Health\&WealthMOD2030, which integrates output from two long-standing income, tax and welfare payments microsimulation models (Static Incomes Model and Australian Population and Policy Simulation Model) and reliable labour force and disease trends data.

- Study findings are based on Survey of Disability, Ageing and Carers respondents' self-reported labour force status and type of chronic disease (diabetes).

- This study provides novel insights into the interdependency of diabetes, labour force participation and costs, with potential implications for clinical care and health policy. It supports preventive health interventions that not only improve health outcomes but also the work capacity of people with diabetes which, in turn, can reduce downstream costs (such as lost personal incomes, extra welfare payments, lost taxation revenue, lost gross domestic product).

addition to disease burden through human suffering and healthcare costs. The government incurs extra welfare payments, lost taxation revenue and lost GDP, along with direct healthcare costs. 


\section{INTRODUCTION}

The prevalence of diabetes in adults (aged 20-79 years) globally was estimated to be 415 million in 2015 , and is projected to increase to 642 million by $2040 .{ }^{1}$ The disability burden of diabetes is associated with a range of symptoms (such as fatigue, increased thirst, frequent urination, blurred vision) and complications which can eventually lead to stroke, blindness, heart attack, kidney failure, amputation and poor psychological well-beingall of which can result in serious impairment, activity limitations and participation restriction. ${ }^{2}$ Various measures of disability burden suggest that the burden of diabetes is also increasing globally. ${ }^{1}{ }^{3}{ }^{4}$ For example, the number of Disability Adjusted Life Years (DALYs) lost to diabetes globally increased by $67.2 \%$ from 12412 DALYs (per 100000 ) in 1990 to 20758 DALYs in 2010. Thus over these 10 years diabetes increased in relative causation of disability from a ranking of 10th to 9 th globally. ${ }^{5}$ Diabetes is a leading cause of deaths each year, with the International Diabetes Federation (2015) reporting that there were 5 million deaths from diabetes worldwide in 2015. ${ }^{1}{ }^{6}$ In addition to the health burden, national governments and international economic/public health organisations, such as the Organisation for Economic Co-operation and Development and the WHO, are also concerned about the negative impact of diabetes on productive life years-defined as the number of people exiting the labour force due to diabetes each year ${ }^{7}$ and the related financial impacts on individuals, and on governments to have sufficient taxation revenue for the healthcare and other services consumed by the ageing population. $^{89}$

The direct (healthcare) costs of diabetes are substantial and rising, with the rise of type 2 diabetes contributing to most of the costs. For type 2 diabetes, this is likely driven by the increasing prevalence of obesity, the ageing population, dietary changes and sedentary lifestyles. ${ }^{3}$ In 2012, the direct medical costs of diagnosed diabetes reached $\$ 176$ billion in the USA-72\% of the total cost of diabetes (\$245 billion). Moreover, medical expenditures among people with diagnosed diabetes were 2.3 times higher than these expenditures would have been in the absence of diabetes. ${ }^{2}$ In Australia, the healthcare costs of diabetes increased from $\$ 811$ million in $2000-2001$ to $\$ 1507$ million in 2008-2009-an increase of $86 \%$ which was considerably greater than the increase in healthcare expenditure for all diseases $(60 \%)$ over this period. In 2008-2009, around $43 \%$ of healthcare expenditure on diabetes was on hospital admitted patient services $(\$ 647$ million), followed by $24 \%$ on out-of-hospital medical services (\$362 million) and 33\% on blood glucose-lowering medicines (\$498 million). ${ }^{10}$ However, these figures only refer to direct (healthcare) costs.

While the direct costs of diabetes are substantial, the full range of indirect costs (ie, lost earnings, lost productivity, lost superannuation, lost taxation revenue, carer costs, extra welfare payments, cost of aids and home/ work modifications, travel costs) are recognised as being even greater. ${ }^{11} 12$ The indirect costs are mostly attributed to lost productivity, with diabetes affecting an individual's ability to maintain employment due to the associated physical disability that reduces their earning capacity. ${ }^{13}$ In the USA in 2012, the cost from reduced productivity due to diagnosed diabetes was $\$ 69$ billion$28 \%$ of the total estimated cost of diagnosed diabetes in 2012. ${ }^{2}$ In Australia in 2012, the estimated cost of lost labour force participation due to diabetes was \$384 million, with resultant extra welfare payments of $\$ 4$ million and lost taxation revenue of $\$ 56$ million. ${ }^{14} \mathrm{~A}$ recent study estimated that $4.2 \%$ of Australians aged 45-64 years were out of the labour force due to diabetes in 2010 (14000), projected to increase to $4.95 \%$ (22 000) by 2030, pushing diabetes from 11th to 9th spot in the ranking of chronic conditions that lead to exits from the labour market among this age group. ${ }^{7}$

There are few studies on the economic costs of lost labour force participation due to diabetes that consider both individual and government perspectives. ${ }^{14}$ Most studies on the indirect costs of diabetes focus only on the loss of earnings for individuals. Resultant reductions in income taxation revenue and increased welfare payments affecting the government are rarely assessed. Although the authors have estimated the economic costs of diabetes through its impact on labour force participation previously (including current income, savings and retirement income, poverty $)^{14-16}$ these estimates are limited to a single year (2009).

The aim of this study is to project the economic costs of diabetes among Australians aged 45-64 years over a 15-year period (2015-2030) using outputs from Australia's first microsimulation model on the current and projected economic costs of ill-health, called Health\&WealthMOD2030. The model integrates data from Australian Bureau of Statistics' (ABS) Survey of Disability, Ageing and Carers (SDACs) 2003 and 2009; output from two long-standing microsimulation models, Static Incomes Model (STINMOD) and Australian Population and, Policy Simulation Model (APPSIM) (both of which are regularly used by government departments to assess the impacts of (economic) policy changes on the population); reliable population and labour force growth data from the Commonwealth Treasury; and reliable chronic disease trends data from the Australian Burden of Disease and Injury Study (2003). This is the first study in Australia and internationally to project a range of indirect costs of diabetes (lost productive life years, extra welfare payments, lost taxation revenue and lost GDP) from both the individual and government perspectives over a long-time horizon.

\section{RESEARCH DESIGN AND METHODS}

\section{Data}

We used outputs from a microsimulation model of the economic costs of ill-health (chronic conditions, disabilities) among Australians aged 45-64 years, called 
Health\&WealthMOD2030, to project the impact of diabetes on labour force participation, personal earnings (income from work), welfare payments, and taxation revenue spending. The development of Health\&WealthMOD2030 is described in detail in Schofield et al (2015). ${ }^{17}$ How the data sources were combined and how data flows through the microsimulation model are illustrated in figure 1.

The base population of the model is comprised of unit record data on individuals aged 45-64 years from the Surveys of Disability, Ageing and Carers (SDACs) 2003 and 2009, conducted by the Australian Bureau of Statistics (ABS). ${ }^{18} 19$ The SDACs are nationally representative household survey data, providing information on individual (age, sex), socioeconomic (highest level of education, income, labour force participation, home ownership, receipt of welfare payments) and health and disability characteristics (chronic conditions, type and degree of disability) of each person in the household.

The SDACs of 2003 and 2009 were reweighted separately using the ABS reweighting algorithm called GREGWT $^{20}$ to account for demographic, labour force, prevalence of chronic conditions and other changes in the population occurring between the survey years (2003, 2009), with the purpose of making the data represent the Australian population in 2015, and then projected to 2020, 2025 and 2030. The mathematical technique is described in Tanton et $a l^{21}$ (2011). The main source for benchmarking data on demographic and socioeconomic changes was Commonwealth Treasury, which provided demographic and labour force projections data. For trends in chronic conditions, we applied the age and sex specific trends in chronic conditions estimated in the 2003 Australian Burden of Disease and Injury Study, ${ }^{22}$ which estimated trends for the period from 2003 to 2023 and assumed that prevalence rates would stabilise afterwards. We calculated proportional changes in chronic condition prevalence and applied these to corresponding diseases in the SDAC data, which were grouped as follows: stroke, cancer (almost stable in men and women), ischaemic heart disease (decreasing trend in men and women), type 2 diabetes (increasing trend in men and women) and chronic obstructive pulmonary disease (stable trend in men; increasing trend in women). For the health conditions without data on trends, age-sex prevalence rates were assumed to be stable over time. Based on proportional changes, the prevalence of health conditions among Australians aged 45-64 years was projected for 2015, 2020, 2025 and 2030 by 5-year age group and sex.

Using a separate microsimulation model, called STINMOD, additional economic data (personal income, welfare payments received, taxes paid) were imputed onto the base data. STINMOD was developed (and is maintained) by the National Centre for Social and Economic Modelling (NATSEM, University of Canberra) (http://www.natsem.canberra.edu.au) and is the principal microsimulation model of Australia's income tax and transfer (welfare) system. ${ }^{23}$ Income and wealth information from STINMOD for 2013 was imputed onto the base population of Health\&WealthMOD2030 (and aged to 2030) by identifying people with similar characteristics on STINMOD and 'donating' their income and wealth information onto the model using a technique commonly used in microsimulation modelling called synthetic matching. ${ }^{24}$ Ten variables, common to both models and significantly related to income, were used to match donor STINMOD records and the base data records: labour force status, income unit type, income quintile, receipt of aged pension, receipt of disability support pensions, sex, age group, hours of work per week, education and home ownership.

The economic data from STINMOD for 2013 were indexed to reflect economic growth projections from

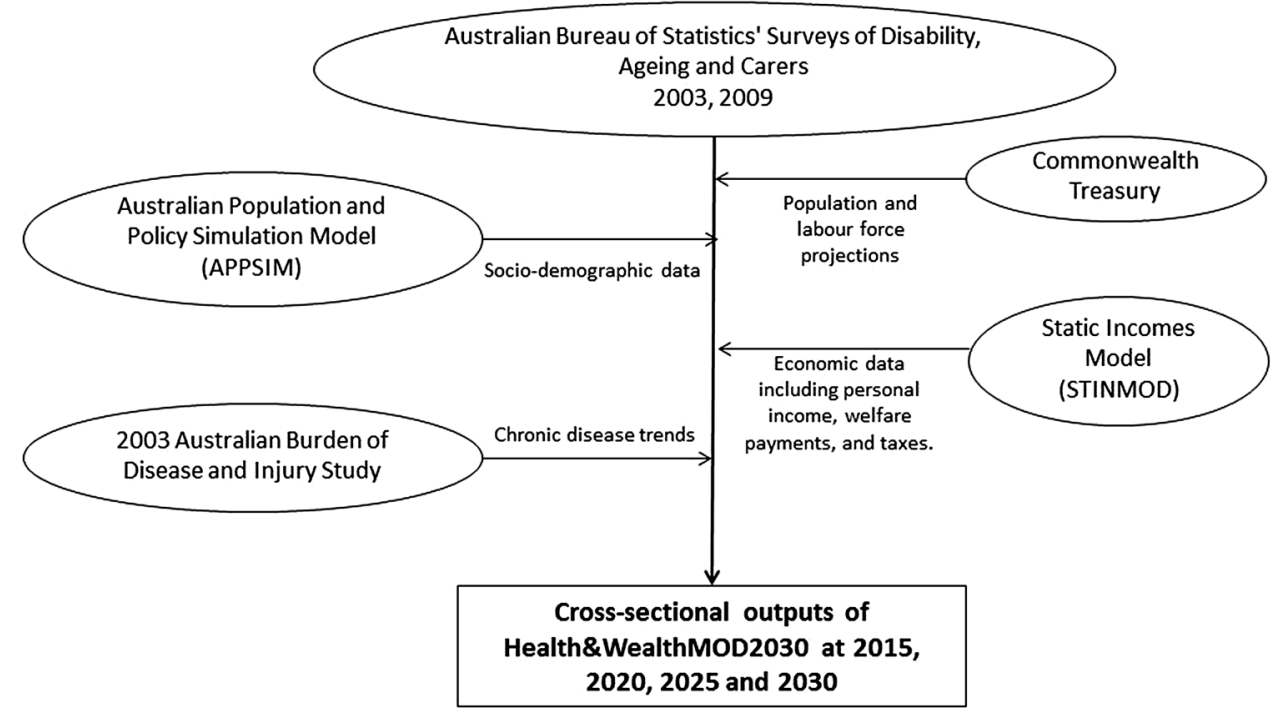

Figure 1 Schematic diagram of Health\&WealthMOD2030. 
2013 to 2030 . Income and taxes paid by individuals were assumed to grow at a rate of $1 \%$ per annum in real terms (Treasury, 2015). ${ }^{25}$ Welfare payments were assumed to have no real growth based on the government's policy of increasing welfare payments (except for aged pension) in line with national Consumer Price Index growth.

Additional sociodemographic data from a third source, a dynamic microsimulation model called APPSIM, ${ }^{26}$ were imputed onto the base population (education, income unit, homeownership, receipt of the disability support pension in 2015, 2020, 2025, 2030). APPSIM was developed by NATSEM in collaboration with 12 Australian Government departments (and is maintained by NATSEM) for the purpose of simulating annual snapshots of the Australian population from 2001 to 2051. APPSIM simulates all major life events (death, migration, marriage, divorce, childbirth, ageing, education, labour force participation, retirement) on the basis of the probability of such events happening to real people in Australia.

The use of the ABS SDAC 2003, 2009 data was approved by the ABS Microdata Review Panel.

\section{Lost productive life years (PLYs) due to diabetes}

In the SDACs, respondents were asked to nominate their current labour force status as either:

1. Employed working full-time

2. Employed working part-time

3. Unemployed looking for full-time work

4. Unemployed looking for part-time work

5. Not in the labour force

Respondents who were not in the labour force were also asked to nominate the main reason they were not working or looking for work. One of the options was 'own ill-health or disability'. All respondents were asked whether they have a main long-term health condition, and to nominate the type of main condition they have from a list of 80 diseases classified by the ABS using International Classification of Diseases 10th Edition (ICD10) codes. Respondents who reported their main health condition was 'diabetes' (ICD10 Codes: E10-14, E74.8, E83.3) were considered to have 'diabetes'. Thus respondents identified as (1) being out of the labour force due to their own ill-health or disability and who (2) reported having diabetes as their main condition, as defined above, were considered to have lost PLYs due to diabetes.

\section{Economic costs}

The following economic costs associated with lost PLYs due to diabetes are projected from 2015 to 2030: lost personal income, extra welfare payments and lost taxation revenue. Personal income consists of labour market earnings, income from other sources generating a return (such as rental properties, investments, interest on cash in bank) and welfare payments. The welfare payments in STINMOD relevant for Australians aged
45-64 years include: Aged Pension, Disability Support Pension, Newstart Allowance (for people looking for work), Carer Payment and Family Tax Benefit (http:// www.humanservices.gov.au/customer/services). The taxes paid by individuals include personal income tax and the Medicare levy.

We calculated the impact of diabetes through lost workers on gross domestic product (GDP) using the Commonwealth Treasury's GDP formula:

$$
\begin{aligned}
& \mathrm{GDP}=(\mathrm{GDP} / \mathrm{H}) \times(\mathrm{H} / \mathrm{EMP}) \times(\mathrm{EMP} / \mathrm{LF}) \\
& \times(\mathrm{LF} / \mathrm{Pop} 15+) \times \mathrm{Pop} 15+
\end{aligned}
$$

where GDP is gross domestic product; $\mathrm{H}$ is total hours worked; EMP is the total number of persons employed; LF is total labour force; and Pop15+ is population aged 15 years and over. $^{27}$

\section{Statistical analysis}

Descriptive analyses were undertaken to establish patterns in the (mean and median) annual income, welfare payments and taxes paid by individuals aged 45-64 years with and without diabetes who are employed full-time, part-time and not in the labour force due to diabetes in 2015, 2020, 2025 and 2030. All figures are expressed in 2013 Australian dollars.

A quantile regression model for (median) weekly income was used to estimate the difference in income received by people in employment (full-time) without diabetes and those out of the labour force due to illhealth with diabetes as their main chronic condition in 2015, 2020, 2025 and 2030. Similar models were estimated for weekly (median) welfare payments and taxes paid. All models included age, sex and highest level of education as covariates.

The national impacts of diabetes, when it leads to an exit from the labour force among those aged 45-64 years, were projected from 2015 to 2030 . $95 \%$ uncertainty intervals (UIs) were generated for these economic outcomes using bootstrapping with 1000 replications for each year.

All analyses were undertaken using SAS V.9.4 (SAS Institute, Cary, North Carolina, USA).

\section{RESULTS}

Among the 25104 respondents aged 45-64 years in the combined SDACs 2003 and 2009, 17913 were in the labour force and 46 were out of the labour force due to diabetes (table 1). A further 1364 were out of the labour force due to ill-health and have conditions other than diabetes; and 5827 were unemployed or out of the labour force due to reasons other than ill-health.

The weighted population aged 45-64 years was 5583500 in 2015. Of these, 3038700 (51.11\%) were employed full-time without diabetes; $180000 \quad(3.03 \%)$ were employed full-time with diabetes; 1141400 (19.20\%) were employed part-time without diabetes; 
Table 1 Mean and median weekly income, welfare payments and taxes of individuals with and without diabetes as main chronic condition, Australian population aged 45-64 years (in 2013 \$A) (unadjusted)

\begin{tabular}{|c|c|c|c|c|c|c|c|c|c|c|c|c|c|c|c|c|c|}
\hline \multirow[b]{2}{*}{ Labour force status* } & \multirow{2}{*}{$\begin{array}{l}\mathrm{N} \\
\text { Survey } \\
\text { records }\end{array}$} & \multicolumn{4}{|l|}{2015} & \multicolumn{4}{|l|}{2020} & \multicolumn{4}{|l|}{2025} & \multicolumn{4}{|l|}{2030} \\
\hline & & $\begin{array}{l}\text { Weighted } \\
\text { population (\%) }\end{array}$ & Mean & SD & Median & $\begin{array}{l}\text { Weighted } \\
\text { population (\%) }\end{array}$ & Mean & SD & Median & $\begin{array}{l}\text { Weighted } \\
\text { population (\%) }\end{array}$ & Mean & SD & $\overline{\text { Median }}$ & $\begin{array}{l}\text { Weighted } \\
\text { population (\%) }\end{array}$ & Mean & SD & Median \\
\hline \multicolumn{18}{|c|}{ Weekly total income $(\$ \mathrm{~A})$ of individuals } \\
\hline $\begin{array}{l}\text { Employed full-time without } \\
\text { diabetes }\end{array}$ & 12161 & $3038700(51.11)$ & 1577.31 & 1520.59 & 1306.81 & $3292800(51.66)$ & 1700.38 & 1634.99 & 1409.88 & 3457200 (51.78) & 1845.73 & 1786.14 & 1514.71 & $3722100(52.20)$ & 1982.32 & 1920.34 & 1605.57 \\
\hline $\begin{array}{l}\text { Employed full-time with } \\
\text { diabetes }\end{array}$ & 521 & $180000(3.03)$ & 1541.17 & 1562.54 & 1194.30 & $215400(3.38)$ & 1655.95 & 1671.20 & 1266.17 & $237000(3.55)$ & 1793.60 & 1780.47 & 1358.29 & $256800(3.60)$ & 1928.15 & 1921.63 & 1446.71 \\
\hline $\begin{array}{l}\text { Employed part-time } \\
\text { without diabetes }\end{array}$ & 4960 & $1141400(19.20)$ & 709.79 & 779.77 & 602.68 & $1271200(19.94)$ & 761.50 & 838.84 & 634.46 & $1353400(20.27)$ & 844.62 & 881.33 & 703.40 & $1464800(20.54)$ & 920.67 & 912.23 & 770.75 \\
\hline $\begin{array}{l}\text { Employed part-time with } \\
\text { diabetes }\end{array}$ & 225 & $76600(1.29)$ & 602.88 & 442.60 & 542.06 & $91700(1.44)$ & 632.62 & 479.66 & 564.19 & $103500(1.55)$ & 698.06 & 522.35 & 613.16 & $111200(1.56)$ & 762.12 & 553.58 & 683.11 \\
\hline $\begin{array}{l}\text { Not in labour force due to } \\
\text { diabetes }\end{array}$ & 46 & $18100(0.30)$ & 315.43 & 158.56 & 393.15 & $20800(0.33)$ & 313.03 & 163.66 & 384.72 & $21300(0.32)$ & 323.85 & 174.60 & 393.15 & $21400(0.30)$ & 331.72 & 186.73 & 385.04 \\
\hline \multicolumn{18}{|c|}{ Weekly welfare income $(\$ \mathrm{~A})$ received by individuals } \\
\hline $\begin{array}{l}\text { Employed full-time without } \\
\text { diabetes }\end{array}$ & 12161 & $3038700(51.11)$ & 18.51 & 62.57 & 0.00 & $3292800(51.66)$ & 17.95 & 61.78 & 0.00 & 3457200 (51.78) & 16.08 & 58.60 & 0.00 & $3722100(52.20)$ & 15.23 & 57.43 & 0.00 \\
\hline $\begin{array}{l}\text { Employed full-time with } \\
\text { diabetes }\end{array}$ & 521 & $180000(3.03)$ & 17.13 & 73.63 & 0.00 & 215400 (3.38) & 17.83 & 76.52 & 0.00 & $237000(3.55)$ & 16.86 & 74.20 & 0.00 & $256800(3.60)$ & 15.95 & 70.50 & 0.00 \\
\hline $\begin{array}{l}\text { Employed part-time } \\
\text { without diabetes }\end{array}$ & 4960 & $1141400(19.20)$ & 74.83 & 142.35 & 0.00 & $1271200(19.94)$ & 73.71 & 142.33 & 0.00 & $1353400(20.27)$ & 67.35 & 136.47 & 0.00 & $1464800(20.54)$ & 63.61 & 132.15 & 0.00 \\
\hline $\begin{array}{l}\text { Employed part-time with } \\
\text { diabetes }\end{array}$ & 225 & $76600(1.29)$ & 117.29 & 167.13 & 4.55 & $91700(1.44)$ & 116.50 & 168.43 & 0.00 & $103500(1.55)$ & 108.28 & 162.89 & 0.00 & $111200(1.56)$ & 101.38 & 156.95 & 0.00 \\
\hline $\begin{array}{l}\text { Not in labour force due to } \\
\text { diabetes }\end{array}$ & 46 & $18100(0.30)$ & 287.99 & 163.85 & 340.91 & $20800(0.33)$ & 282.65 & 165.83 & 321.87 & $21300(0.32)$ & 285.04 & 167.59 & 321.87 & $21400(0.30)$ & 282.01 & 170.91 & 321.87 \\
\hline \multicolumn{18}{|c|}{ Weekly tax paid (includes Medicare levy) (\$A) by individuals } \\
\hline $\begin{array}{l}\text { Employed full-time without } \\
\text { diabetes }\end{array}$ & 12161 & $3038700(51.11)$ & 347.33 & 474.54 & 238.49 & 3292800 (51.66) & 378.56 & 514.74 & 262.64 & 3457200 (51.78) & 413.99 & 559.76 & 286.92 & 3722100 (52.20) & 447.51 & 605.78 & 306.30 \\
\hline $\begin{array}{l}\text { Employed full-time with } \\
\text { diabetes }\end{array}$ & 521 & $180000(3.03)$ & 331.70 & 531.11 & 211.07 & 215400 (3.38) & 361.37 & 576.04 & 229.84 & 237000 (3.55) & 394.13 & 618.49 & 247.80 & $256800(3.60)$ & 428.07 & 679.61 & 262.47 \\
\hline $\begin{array}{l}\text { Employed part-time } \\
\text { without diabetes }\end{array}$ & 4960 & 1141400 (19.20) & 81.06 & 198.11 & 16.55 & $1271200(19.94)$ & 89.91 & 215.12 & 20.05 & $1353400(20.27)$ & 101.42 & 225.05 & 29.33 & $1464800(20.54)$ & 110.72 & 232.41 & 37.87 \\
\hline $\begin{array}{l}\text { Employed part-time with } \\
\text { diabetes }\end{array}$ & 225 & $76600(1.29)$ & 48.46 & 103.39 & 0.00 & $91700(1.44)$ & 52.91 & 113.10 & 0.00 & $103500(1.55)$ & 62.32 & 124.70 & 0.00 & $111200(1.56)$ & 70.73 & 134.19 & 9.22 \\
\hline $\begin{array}{l}\text { Not in labour force due to } \\
\text { diabetes }\end{array}$ & 46 & $18100(0.30)$ & -0.55 & 0.00 & 0.00 & $20800(0.33)$ & -0.14 & 0.55 & 0.00 & $21300(0.32)$ & -0.14 & 0.55 & 0.00 & $21400(0.30)$ & -0.16 & 0.59 & 0.00 \\
\hline
\end{tabular}

There were 25104 people aged 45-64 years in the concatenated SDAC 2003 and 2009 data. Of these, 17913 people were identified as being in one of the labour force categories listed in table 1 . A further 1364 were not in the labour

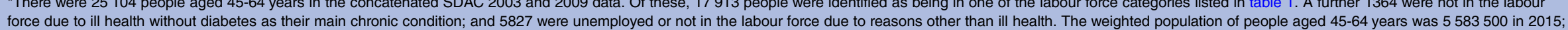
5980000 in 2020; 6262000 in 2025; and 6690100 in 2030.

SDAC, Survey of Disability, Ageing and Carers. 
$76600(1.29 \%)$ were employed part-time with diabetes; and $18100(0.30 \%)$ were out of the labour force due to diabetes (ie, lost PLYs due to diabetes) (table 1, 2nd column).

People who were out of the labour force due to their diabetes had a median weekly income (income derived from all sources including welfare payments) of \$A393.15 in 2015 (expressed in 2013 dollars). Notably, their income was only $30 \%$ of the median weekly income of people employed full-time without diabetes (table 1, 5th column). People out of the labour force due to diabetes also had a lower median income compared to those with diabetes who were still able to work part-time (\$A542.06) or full-time (\$A1194.30). Of their total weekly income, people out of the labour force due to their diabetes received a median of $\$ A 340.91$ in weekly welfare payments, whereas those in the labour force received $\$ A 0$ in welfare payments in 2015. People out of the labour force due to their diabetes paid no median weekly taxes, whereas those employed in fulltime work without diabetes paid \$A238.49 per week in tax in 2015.

The population aged 45-64 years was projected to reach 6690100 by 2030. Of these, $3722100(52.20 \%)$ people are employed full-time without diabetes; 256800 $(3.60 \%)$ are employed full-time with diabetes; 1464800 (20.54\%) are employed part-time without diabetes; $111200(1.56 \%)$ are employed part-time with diabetes; and $21400(0.30 \%)$ are out of the labour force (lost PLYs) due to their diabetes. Those with lost PLYs due to diabetes are projected to receive $\$ A 385.04$ in median income each week, \$A321.87 in median welfare payments each week and pay \$A0 in income taxes in 2030, expressed in 2013 dollars (table 1, last column).

Compared to people employed full-time without diabetes, those out of the labour force due to diabetes received \$A665.06 (95\% UI: \$A553.82 to \$A834.57) less in median weekly income (adjusted for age, sex and education) in 2015 (table 2, 1st column). They also received significantly more in welfare payments (an extra $\$$ A340.91 each week, 95\% UI: $\$$ A238.50 to $\$ \mathrm{~A} 413.50)$ and pay significantly less in tax (\$A153.81 each week, 95\% UI: \$A144.84 to \$A190.77) compared to people employed full-time without diabetes.

The differences in median weekly income, welfare payments and taxes paid (adjusted for age, sex and education) between people with lost PLYs due to diabetes and those employed full-time without diabetes were also estimated for 2030 (table 2, last two columns). Lost income for people out of the labour force due to diabetes increased from \$A665.06 each week in 2015 (95\% UI: $\$ \mathrm{~A} 553.82$ to $\$ \mathrm{~A} 834.57)$ to $\$ \mathrm{~A} 934.70$ each week in 2030 (95\% UI: $\$ A 827.68$ to $\$ A 1095.37$ ) in real terms, compared to the income of people employed full-time without diabetes. This increase was largely due to projected real growth in wages over the period, while no projected real growth in welfare payments for those not in the labour force due to diabetes. Historically earnings

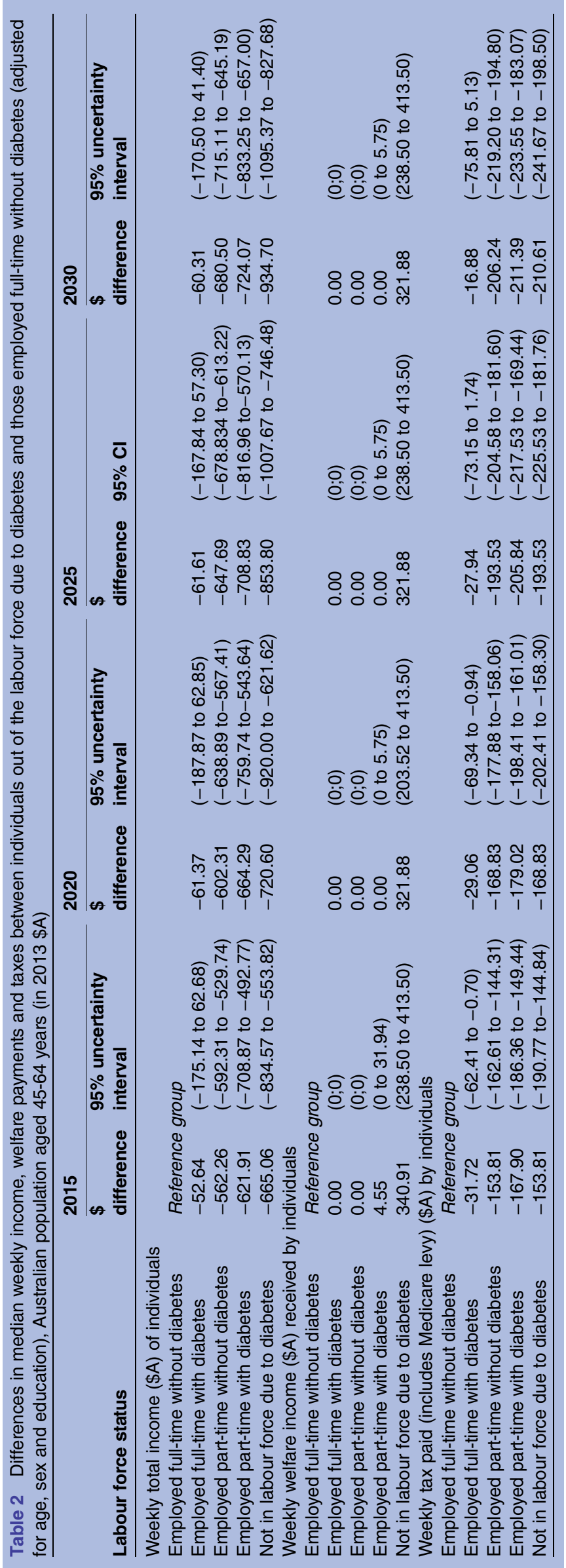


in Australia grow at a rate that is one per cent above inflation. ${ }^{28} 29$ People with lost PLYs due to diabetes paid \$A153.81 each week (95\% UI: \$A144.84 to \$A190.77) less in income taxes than those employed full-time without diabetes in 2015, increasing to $\$ A 210.61$ each week (95\% UI: $\$$ A 198.50 to $\$$ A241.67) by 2030 .

The national impact of diabetes when it causes lost PLYs consists of \$A467 million (95\% UI: \$A340 million to $\$ A 662$ million) in lost annual income in 2015 , and is projected to reach $\$$ A807 million $(95 \%$ UI: $\$ A 617$ million to $\$$ A1065 million) by 2030 -a $42 \%$ increase in lost income for this period (figure 2). Additional welfare payments associated with lost PLYs due to diabetes is projected to increase by $13 \%$ in real terms over the next 15 years, from \$A311 million (95\% UI: \$A213 million to $\$$ A462 million) per year in 2015 to $\$$ A350 million (95\% UI: \$A245 million to \$A546 million) in 2030 (figure 3). Finally, lost annual taxation revenue is projected to increase by $63 \%$ in real terms by 2030 , from $\$ A 102$ million (95\% UI: \$A82 million to \$A139 million) in 2015 to $\$$ A166 million (95\% UI: \$A127 million to \$A219 million) in 2030 (figure 4).

Exits from the labour market because of diabetes also produce significant GDP losses each year (table 3), which were calculated in two stages. Using Health\&WealthMOD2030, we calculated the number of workers (full-time or part-time) who are no longer working due to diabetes (missing workers) to be 17,600, 20,200, 20900 and 20900 in 2015, 2020, 2025 and 2030, respectively. Using Treasury's GDP formula, we calculated the GDP losses owing to missing workers due to diabetes to be $\$$ A2.1 billion, $\$$ A2.5 billion, $\$$ A2.7 billion and $\$$ A2.9 billion in 2015, 2020, 2025 and 2030, respectively. If these (potential) workers had their diabetes either prevented or treated to the point where they could remain in the work force, the predicted gain in GDP is up to $0.14 \%$ each year.

\section{DISCUSSION}

The direct (healthcare) cost of diabetes was \$A811 million in 2000-2001, increasing to $\$ A 1507$ million in 2008-2009-an increase of $86 \%$. The majority of this health funding was spent on hospital stays and (prescribed) medicines, followed closely by non-hospital medical services (such as general practitioner, blood glucose testing, dietician)..$^{10}$ However, this study has demonstrated that the indirect costs of diabetes through lost productive life years are considerable, both at the individual and national level. People aged 4564 years who exited the labour force because of their diabetes had a median weekly (personal) income of only $\$$ A393.15 in 2015 , whereas those employed fulltime without diabetes received an income over three times greater than this amount (\$A1306.81). By 2030, the income gap between these two groups is projected to be even greater; with those out of the labour force due to their diabetes receiving an annual income four times lower than that of full-time workers without diabetes. The national impact of diabetes through the lost labour force participation of people aged 45-64 years is projected to reach $\$ A 807$ million in lost income, $\$ A 350$ million in extra welfare payments, \$A166 million in lost taxation revenue and \$A2.9 billion in lost GDP by 2030.

A number of overseas studies have also demonstrated that diabetes has a significant impact on labour force participation and earnings. For example, a Canadian study found that people with diabetes complications were twice as likely to be out of the labour force

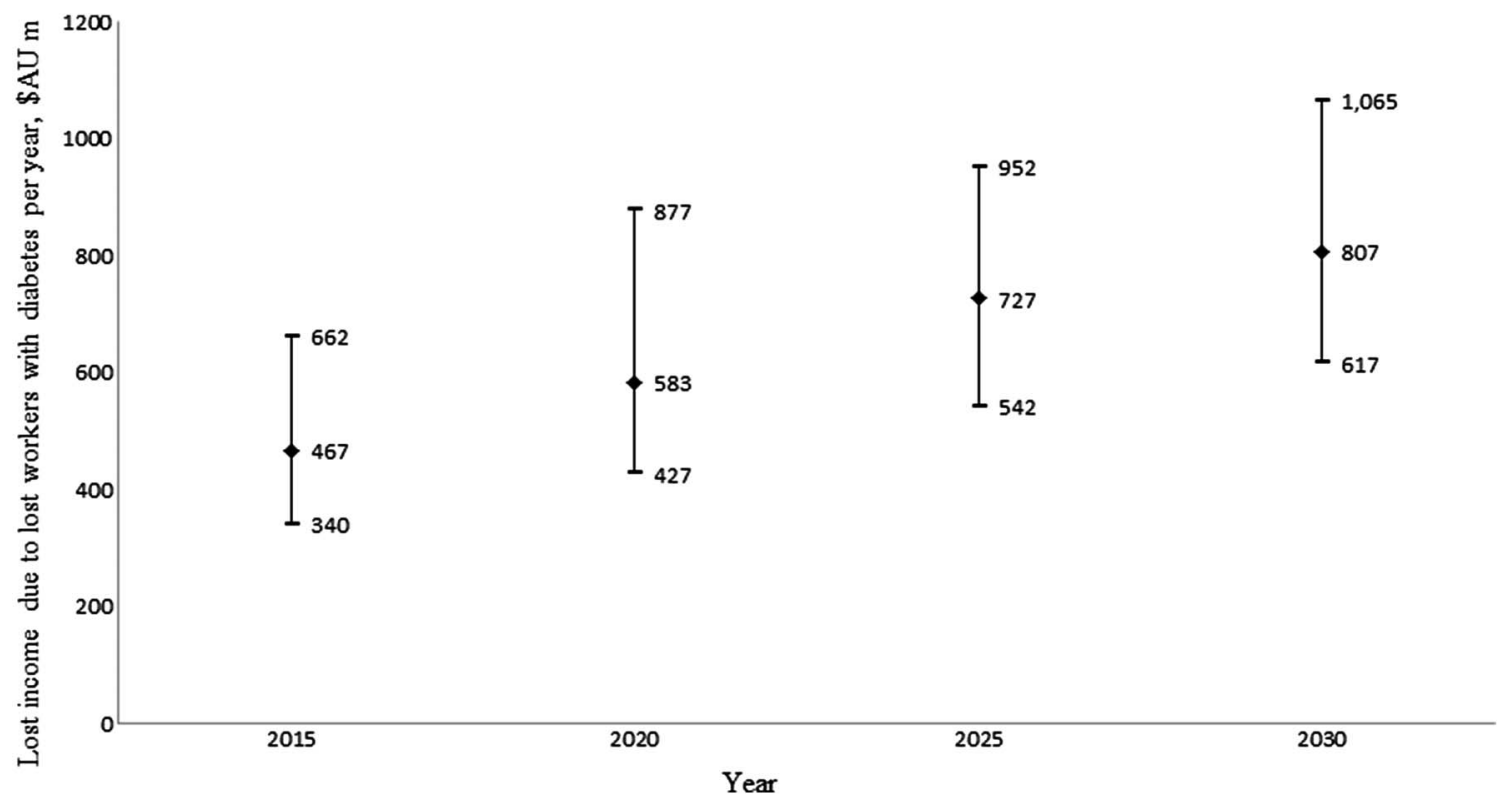

Figure 2 National lost income due to lost workers (full-time and part-time) because of diabetes per year (\$A millions, with $95 \%$ uncertainty intervals). 


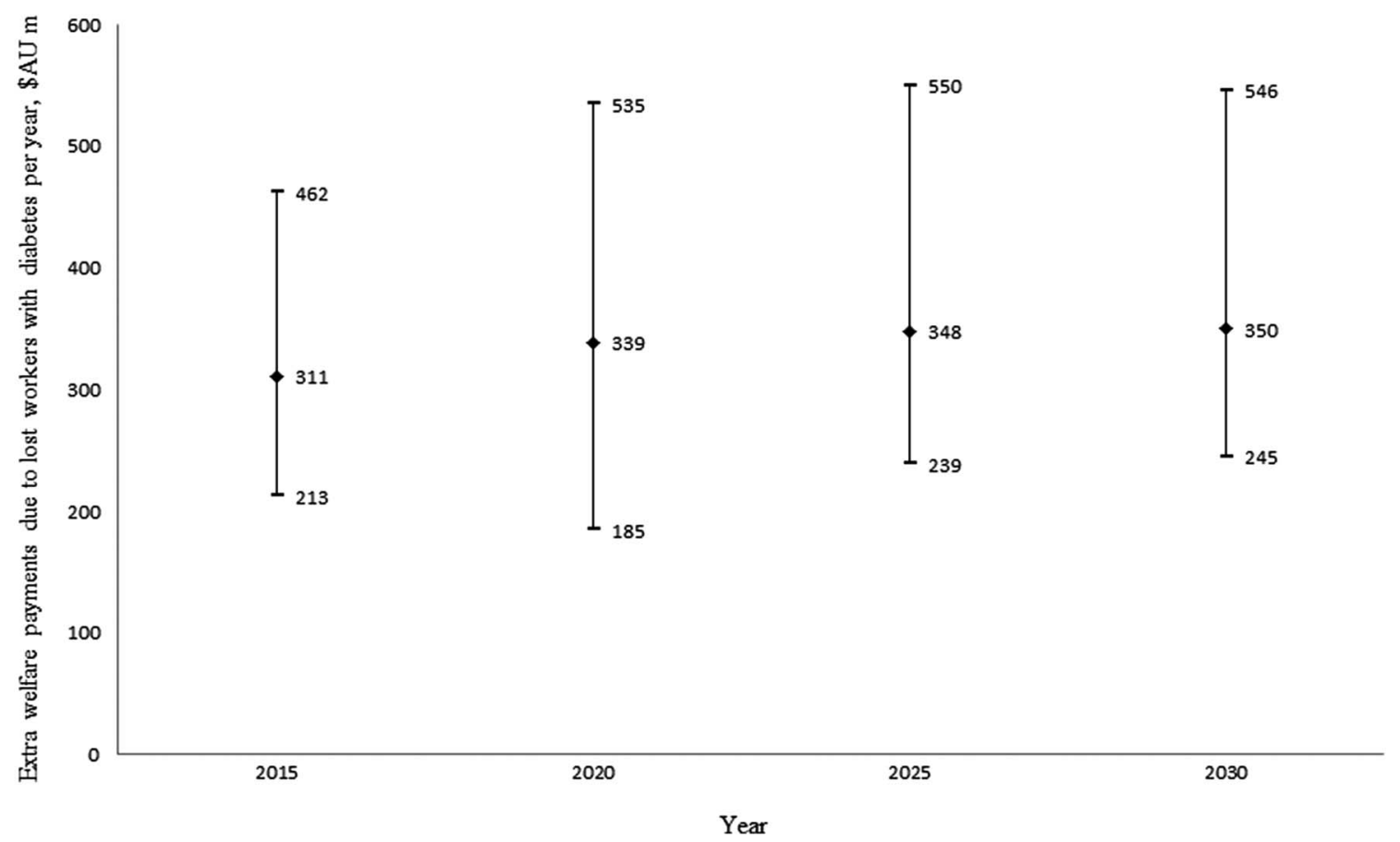

Figure 3 Extra welfare payments due to lost workers (full-time and part-time) because of diabetes per year (\$A millions, with $95 \%$ uncertainty intervals).

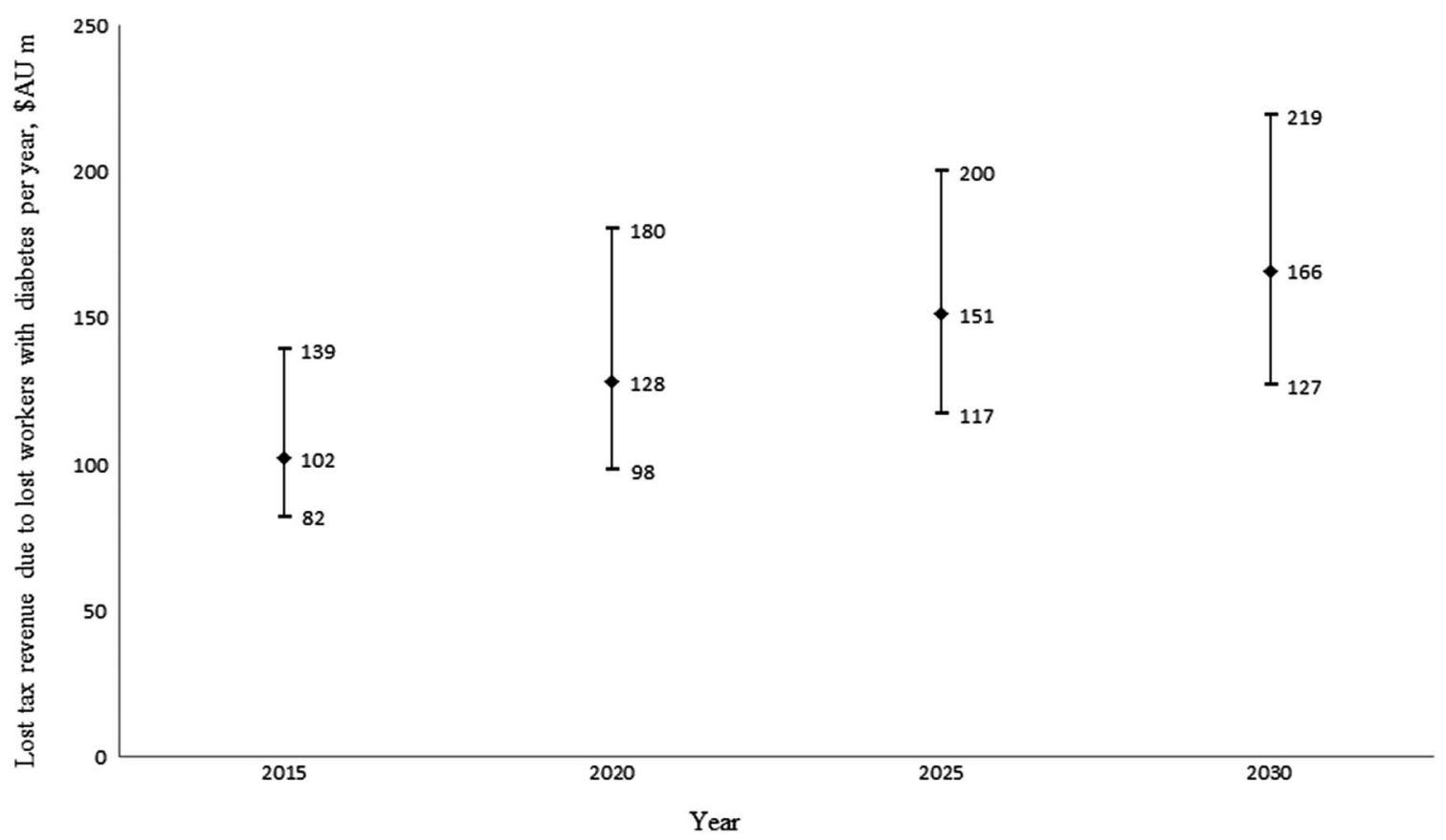

Figure 4 National lost income tax revenue due to lost workers (full-time and part-time) because of diabetes per year ( $\$ \mathrm{~A}$ millions, with $95 \%$ uncertainty intervals).

compared to non-diabetics in the working-age population. ${ }^{13}$ Similar findings (including valuing the lost productivity due to diabetes in terms of lost income, extra welfare payments) have been made in studies from the USA $^{30-32}$ and Europe. ${ }^{33}$

This study has some limitations. Findings are based on SDAC respondents' self-reported chronic disease and labour force status. Although self-reported health and employment status are regarded as valid measures for such studies, ${ }^{34} 35$ there is the potential for bias in results. The SDACs are cross-sectional data; however, several survey questions have been designed in such a way as to capture causal relationships. For example, the SDACs have 'own ill-health or disability' as a category for the main reason respondents are out of the labour force (a causal relationship). 
Table 3 Lost gross domestic product owing to missing workers* aged 45-64 years due to diabetes, 2015-2030 (\$A millions)†

\begin{tabular}{lllll}
\hline & $\mathbf{2 0 1 5}$ & $\mathbf{2 0 2 0}$ & $\mathbf{2 0 2 5}$ & $\mathbf{2 0 3 0}$ \\
\hline Projected GDP & $\$ 1483861$ & $\$ 1678852$ & $\$ 1899467$ & $\$ 2149073$ \\
Lost GDP owing to missing workers due to diabetes $\dagger$ & $\$ 2062$ & $\$ 2472$ & $\$ 2715$ & $\$ 2902$ \\
$\begin{array}{l}\text { Potential \% gain in total GDP if able to keep missing workers due to } \\
\text { diabetes in the labour force }\end{array}$ & $0.14 \%$ & $0.15 \%$ & $0.14 \%$ & $0.14 \%$
\end{tabular}

${ }^{*}$ Missing (or lost) workers per year:

Of the 18100 people out of the labour force due to diabetes in 2015 , it is projected $12800(70.56 \%)$ move into full-time employment and $4800(26.50 \%)$ move into part-time employment. The residual 500 people out of the labour force due to diabetes remain in unemployment. Of the 20800 people out of the labour force due to diabetes in 2020 , it is projected $14600(70.31 \%)$ move into full-time employment and $5600(27.14 \%)$ move into part-time employment. The residual 600 people out of the labour force due to diabetes remain in unemployment. Of the 21300 people out of the labour force due to diabetes in 2025 , it is projected $15000(70.11 \%)$ move into full-time employment and $5900(27.45 \%)$ move into part-time employment. The residual 400 people out of the labour force due to diabetes remain in unemployment. Of the 21400 people out of the labour force due to diabetes in 2030, it is projected $15000(70.03 \%)$ move into full-time employment and $5900(27.56 \%)$ move into part-time employment. The residual 500 people out of the labour force due to diabetes remain in unemployment. tImpacts on GDP are based on projections of $17600,20200,20900$ and 20900 missing workers (full-time or part-time) due to diabetes in 2015, 2020, 2025 and 2030, respectively.

GDP, gross domestic product.

The focus of this study was on the economic impacts of diabetes on individuals (such as lost labour force participation and lost income) and how their lost productivity translates into costs to government (lost income tax revenue, extra welfare payments) and society (lost GDP). While quantifying these indirect costs addresses some of the research gap, there are other costs that could also be considered such as informal carer costs. We did not seek to measure these additional costs in the present study; however, we note that our previous work on the lost labour force participation of people caring for someone with a chronic condition in Australia showed that $60 \%$ of primary carers caring for someone with endocrine/ nutritional and metabolic disorders (ie, thyroid, diabetes and high-blood pressure) were not in the labour force, which placed this disease group as the fifth top worklimiting conditions for caregivers. ${ }^{36}$ Thus the indirect costs of diabetes are likely to be even larger after taking more of these types of costs into account.

With the health burden of the condition being so large, the total cost of diabetes (direct and indirect costs) for national governments is correspondingly significant and thus an issue requiring urgent policy attention. ${ }^{3} 14$ Consequently, several governments (such as The Fit for Work Europe Coalition) have put forward the case for counting labour productivity as a relevant outcome measure in health investment decisions, especially decisions involving patients with long-term health conditions. ${ }^{37}$

The ageing of the global population has also highlighted the need to focus on the retention older workers. $^{38}$ In Australia, $4.15 \%$ of people aged 45-64 years who have diabetes are not in the labour force, representing a pool of people who might have worked had they not had this condition. ${ }^{39}$ Australia, like most other developed countries, will need to maximise the labour force participation of its older workers in order to have sufficient taxation revenue from which to fund the healthcare and services used by the ageing population. ${ }^{40}$
Several randomised controlled trials have demonstrated that lifestyle and pharmacological (metformin) interventions are effective in preventing or delaying type 2 diabetes in high-risk individuals (ie, people with impaired fasting glucose or impaired glucose tolerance). ${ }^{41-43}$ Bertram et al (2010) assessed both the health effects and direct (medical) costs of a number of interventions to prevent diabetes. The authors concluded that screening to identify people with pre-diabetes, followed with treatment using metformin or diet and exercise for those at risk were the most cost-effective interventions in preventing or delaying the onset of the disease. ${ }^{44}$ A recent Australian economic study has shown that diabetes prevention interventions using screening and treatment (metformin or a lifestyle intervention targeting diet and exercise) in pre-diabetic adults (aged 45-64 years) could increase labour force participation and reduce income losses. ${ }^{45}$

Reduced income among those who have to exit from the labour force due to their diabetes can also lead to inadequate (personal) finances for basic healthcare and services. ${ }^{46}$ A study from the USA found a high correlation between chronic illness and financial stress, with one-quarter of bankruptcies attributable to chronic illness. ${ }^{46}$ A recent study from Australia has shown that while everyone employed full-time or part-time in 2010 has accumulated some savings at the traditional retirement age of 65 years mainly due to compulsory superannuation savings, only $91 \%$ of people who are out of the labour force due to diabetes have accumulated some savings by age 65 years, ${ }^{15}$ leaving them with minimal savings to cover the higher healthcare costs incurred in old age.

Diabetes is increasing in prevalence worldwide. It is also becoming more common among the working-age population, particularly those aged 45-64 years. ${ }^{30}$ Consequently, the negative impact of diabetes on labour force participation and the magnitude of the related costs (lost income, extra welfare payments, lost taxation 
revenue, lost GDP) will increase over time. To reduce the substantial costs of early retirement due to diabetes, investment in disease prevention is needed, which is aligned with the health platform of the current Australian Government in recognising that chronic disease prevention helps to increase labour force participation. It is acknowledged that prevention will improve the health of the general population and help to maintain economic growth by sustaining human resources in production, as well as helping future governments ensuring they have sufficient revenue to fund the healthcare needs of the ageing population. ${ }^{40}$

\section{Author affiliations}

${ }^{1}$ Faculty of Pharmacy, Charles Perkins Centre, The University of Sydney, Sydney, New South Wales, Australia

${ }^{2}$ Murdoch Children's Research Institute, Royal Children's Hospital Flemington Road, Parkville, Victoria, Australia

${ }^{3}$ Garvan Institute of Medical Research, Sydney, New South Wales, Australia ${ }^{4}$ University Centre for Rural Health, School of Public Health, The University of Sydney, Lismore, New South Wales, Australia

${ }^{5}$ Faculty of Medicine and Biomedical Sciences, School of Public Health, University of Queensland, Brisbane, Queensland, Australia

${ }^{6}$ National Centre for Social and Economic Modelling, University of Canberra, Canberra, Australian Capital Territory, Australia

Contributors DS conceived and led the study. DS, RNS, MEP, JLV, SJK, RT made substantial contributions to study conception and design. DS, RNS, RT, JLV, SJK made substantial contributions to acquisition of data. RNS, MMC analysed data and DS, RNS, MMC, JLV, SJK, RT, MEP made substantial contributions to the interpretation of the results. MMC wrote the first draft of the article and DS, MMC, RNS, RT, JLV, SJK, MEP were responsible for drafting the article or revising it critically for important intellectual content. DS, RNS, SJK, RT, JLV, MEP developed Health\&WealthMOD2030. All authors gave final approval of the version of the article to be published.

Funding The development of the microsimulation model used in this research, Health\&WealthMOD2030, is funded by the Australian Research Council Linkage Project grant (under grant LP100100158). Pfizer Australia is a partner to the grant. MP is supported by fellowships from the NHMRC, the Cancer Institute NSW and the Sydney Medical School Foundation.

All authors are independent from the funding sources, and the funding sources (including Pfizer Australia) played no part in the research design, analysis, formulation or interpretation of the results, decision to publish the findings, nor any other part of the research process.

Competing interests None declared.

Ethics approval The use of the ABS SDAC 2003, 2009 data was approved by the ABS Microdata Review Panel.

Provenance and peer review Not commissioned; externally peer reviewed.

Data sharing statement No additional data are available.

Open Access This is an Open Access article distributed in accordance with the Creative Commons Attribution Non Commercial (CC BY-NC 4.0) license, which permits others to distribute, remix, adapt, build upon this work noncommercially, and license their derivative works on different terms, provided the original work is properly cited and the use is non-commercial. See: http:// creativecommons.org/licenses/by-nc/4.0/

\section{REFERENCES}

1. International Diabetes Federation. IDF diabetes atlas, seventh edition. Brussels: International Diabetes Federation, 2015.

2. American Diabetes Association. Economic costs of diabetes in the U.S. in 2012. Diabetes Care 2013;36:1033-46.

3. Baker IDI Heart and Diabetes Institute. Diabetes: the silent pandemic and its impact on Australia. 2012.
4. Cefalu WT, Petersen PM, Ratner RE. The alarming and rising costs of diabetes and prediabetes: a call for action!. Diabetes Care 2014;37:3137-8.

5. King H, Aubert R, Herman WH. Global burden of diabetes, 19952025: prevalence, numerical estimates, and projections. Diabetes Care 1998;21:1414-31

6. Lozano R, Naghavi M, Foreman K, et al. Global and regional mortality from 235 causes of death for 20 age groups in 1990 and 2010: a systematic analysis for the Global Burden of Disease Study 2010. Lancet 2012;380:2095-128.

7. Schofield DJ, Shrestha RN, Cunich M, et al. Lost productive life years caused by chronic conditions in Australians aged 45-64 years, 2010-2030. Med J Aust 2015;203:260.e1-6.

8. Organisation for Economic Co-operation and Development. Sickness, disability and work: breaking the barriers. Paris: OECD Publishing, 2007.

9. World Health Organisation. The impact of chronic disease in high income countries. Geneva: World Health Organisation, 2005.

10. Australian Institute of Health and Welfare. Diabetes expenditure in Australia 2008-09, Cat. no. CVD 62. Canberra: AlHW, 2013.

11. Colagiuri SCR, Conway B, Grainger D, et al. DiabCo\$t Australia assessing the burden of type 2 diabetes in Australia. Canberra: Diabetes Australia, 2003.

12. Colagiuri SBA, Gomez M, Fitzgerald B, et al. DiabCo\$t Australia type 1: assessing the burden of type 1 diabetes in Australia. Diabetes Australia. Canberra: 2009.

13. Kraut $A$, Tate $R$, Walld $R$, et al. Impact of diabetes on employment income in Manitoba, Canada. Diabetes Care 2001;24:64-8.

14. Schofield D, Cunich M, Shrestha RN, et al. The economic impact of diabetes through lost labour force participation on individuals and government: evidence from a microsimulation model. BMC Public Health 2014;14:220.

15. Schofield D, Cunich M, Kelly S, et al. The impact of diabetes on the labour force participation, savings and retirement income of workers aged 45-64 years in Australia. PLOS ONE 2015;10:e0116860.

16. Schofield DJ, Cunich M, Shrestha RN, et al. The impact of diabetes on the labour force participation and income poverty of workers aged 45-64 years in Australia. PLoS ONE 2014;9:e89360.

17. Schofield D, Shrestha R, Kelly S, et al. Health\&WealthMOD2030: a microsimulation model of the long term economic impacts of disease on the labour force participation of Australians aged 45-64 years old. Int J Microsimulation 2014;7:94-118.

18. Australian Bureau of Statistics. Information paper-basic confidentialised unit record file: survey of disability, ageing and carers 2003 (reissue). Canberra: Australian Bureau of Statistics, 2005.

19. Australian Bureau of Statistics. Information paper: disability, ageing and carers, Australia: user guide 2009. Canberra: Australian Bureau of Statistics, 2011.

20. Bell P. GREGWT and TABLE macros-users guide. Canberra: Australian Bureau of Statistics, 2000

21. Tanton $\mathrm{R}$, Vidyattama $\mathrm{Y}$, Nepal $\mathrm{B}$, et al. Small area estimation using a reweighting algorithm. $J R$ Statist Soc A 2011;174:931-51.

22. Begg SJ, Vos T, Barker B, et al. Burden of disease and injury in Australia in the new millennium: measuring health loss from diseases, injuries and risk factors. Med J Aust 2008;188:36-40.

23. Lambert S, Percival R, Schofield D, et al. An introduction to STINMOD: a static microsimulation model. Canberra: NATSEM, 1994 STINMOD Technical Paper No. 1.

24. Rässler S. Statistical matching: a frequentist theory, practical applications, and alternative Bayesian approaches. New York: Springer-Verlag New York, 2002.

25. Treasury. Budget Paper No 1: Budget Strategy and Outlook 2015-16. Canberra: Commonwealth Treasury, 2015.

26. Keegan M, Kelly S. APPSIM-dynamic microsimulation modelling of social security and taxation. Canberra: National Centre for Social and Economic Modelling, University of Canberra, 2009.

27. Commonwealth Treasury. Intergenerational report 2007. Canberra: Commonwealth of Australia, 2007.

28. Australian Bureau of Statistics. Average weekly earnings, Australia, May 2016, Catalogue number 6302.0. Canberra: ABS, 2016.

29. Australian Bureau of Statistics. Consumer price index, Australia, Jun 2016, Catalouge number 63401.0. Canberra: ABS, 2016.

30. Tunceli K, Bradley CJ, Nerenz D, et al. The impact of diabetes on employment and work productivity. Diabetes Care 2005;28:2662-7.

31. Vijan S, Hayward RA, Langa KM. The impact of diabetes on workforce participation: results from a national household sample. Health Serv Res 2004;39(Pt 1):1653-70.

32. daCosta DiBonaventura M, Cappelleri J, Joshi AV. A longitudinal assessment of painful diabetic peripheral neuropathy on health status, productivity, and healthcare utilization and cost. Pain Med 2011;12:18-26. 
33. Alavinia SM, Burdorf A. Unemployment and retirement and ill-health: a crosssectional analysis across European countries. Int Arch Occup Environ Health 2008;82:39-45.

34. Wannamethee G, Shaper AG. Self-assessment of health status and mortality in middle-aged British men. Int $J$ Epidemiol 1991;20:239-45.

35. Cai L, Kalb G. Health status and labour force participation: evidence from the HILDA survey Melbourne: Melbourne Institute of Applied Economic and Social Research, 2004.

36. Schofield D, Cunich M, Shrestha R, et al. The impact of chronic conditions of care recipients on the labour force participation of informal carers in Australia: which conditions are associated with higher rates of non-participation in the labour force? BMC Public Health 2014;14:561.

37. Fit for Work Europe. Making work count-how Health Technology Assessment can keep Europeans in work, 2012.

38. Organisation for Economic Co-operation and Development. The labour force participation of older workers: the effects of pension and early retirement schemes Paris: OECD Economics Department. 2004. (cited 2004 May). http://www.oecd.org/dataoecd/25/4/ 31743847.pdf

39. Schofield DJ, Shrestha RN, Passey ME, et al. Chronic disease and labour force participation among older Australians. Med J Aust 2008;189:447.
40. Costello P. Intergenerational report 2007. Canberra: Commonwealth of Australia, 2007.

41. Gillies CL, Abrams KR, Lambert PC, et al. Pharmacological and lifestyle interventions to prevent or delay type 2 diabetes in people with impaired glucose tolerance: systematic review and meta-analysis. BMJ 2007;334:299.

42. Gillies CL, Lambert PC, Abrams KR, et al. Different strategies for screening and prevention of type 2 diabetes in adults: cost-effectiveness analysis. BMJ 2008;336:1180-5.

43. Knowler WC, Barrett-Connor E, Fowler SE, et al., Diabetes Prevention Program Research Group. Reduction in the incidence of type 2 diabetes with lifestyle intervention or Metformin. N Engl J Med 2002;346:393-403.

44. Bertram MY, Lim SS, Barendregt JJ, et al. Assessing the cost-effectiveness of drug and lifestyle interventions following opportunistic screening for pre-diabetes in primary care. Diabetologia 2010;53:875-81.

45. Passey ME, Shrestha RN, Bertram MY, et al. The impact of diabetes prevention on labour force participation and income of older Australians: an economic study. BMC Public Health 2012;12:16.

46. Himmelstein DU, Warren E, Thorne D, et al. Illness and injury as contributors to bankruptcy. Health Aff (Millwood) 2005 $24: 1$. 